\title{
THE EFFECTS OF LONG TIME EXPOSURE ON ALLOY 718
}

\author{
S.T.Wlodek* and R.D.Field** \\ GE Aircraft Engines Cincinnati, OH 45215
}

\begin{abstract}
Measurements of gamma prime $\left(\gamma^{\prime}\right)$ and gamma double prime $\left(\gamma^{\prime \prime}\right)$ size were made on Inconel alloy 718 exposed for up to $50,000 \mathrm{hr}$ 's, in the temperature range of 538 to $704{ }^{\circ} \mathrm{C}$ $\left(1000\right.$ to $\left.1300^{\circ} \mathrm{F}\right)$. All materials were from either the original Barker, Ross and Radavich study, where the specimens were exposed under stress, or the more recent Korth work that utilized unstressed exposures. The diameter of the $\gamma^{\prime}$ and $\gamma^{\prime \prime}$ phases, $\mathrm{D}^{\prime}$ and $\mathrm{D}^{\prime \prime}$ ( in $\left.\mu \mathrm{m}\right)$, were measured and could be correlated through a Larsen-Miller parameter $(\mathrm{P}=\mathrm{T}[25+\log \mathrm{t} \mid)$ to the temperature ( $\mathrm{T}$ in ${ }^{\circ} \mathrm{K}$ ) and the time of exposure ( $\mathrm{t}$ in $\mathrm{hr}$ 's $)$. The following relationships were established :

$$
\begin{array}{lll}
\text { for } \gamma^{\prime \prime}, & \log \mathrm{P}=\frac{\log \mathrm{D}^{\prime}+7.1158}{0.21314} & \mathrm{R}^{2}=0.94 \\
\text { for } \gamma^{\prime \prime}, & \log \mathrm{P}=\frac{\log \mathrm{D}^{\prime \prime}+8.60597}{0.29265} & \mathrm{R}^{2}=0.96
\end{array}
$$

These relationships were derived using materials of varying chemistry, processing and heat treatment, exposed with and without stress. In addition, where suitable mechanical data were available, it was possible to establish regression equations between the $\gamma$ " diameter and simple mechanical properties. High resolution scanning electron microscopy, that allows accurate precipitate measurement, can thus be used to estimate service temperature and approximate residual properties in parts after prolonged service. This technique is effective regardless of the stress level, or slight, in specification, variations in chemistry, processing or heat treatment.

Detailed AEM studies were performed on material exposed $50,000 \mathrm{hr}$ 's. at $649 \mathrm{C}\left(1200^{\circ} \mathrm{F}\right)$. These lead to the definite identification of $\alpha-\mathrm{Cr}$, a high $\mathrm{Cr}$ and $\mathrm{Mo}$ Laves phase, and small amounts of a sigma phase, as forming during prolonged exposure, in addition to the standard $\gamma^{\prime}$, $\gamma^{\prime \prime}$, delta, and MC phases. More extensive SEM studies, backed up by energy dispersive $\mathbf{x}-$ ray analysis, were utilized to follow these precipitation reactions over the whole range of time and temperature studied here. It was possible to conclude that the precipitation of $\alpha$ - $\mathrm{Cr}$ and the other minor phases in alloy 718 are driven by the almost complete rejection of $\mathrm{Cr}$ and $\mathrm{Mo}$ that results in advance of the growing delta phases.
\end{abstract}

* Gamma Prime Consultants, San Diego, CA 92127-1272. ** Los Alamos National Laboratories, Los Alamos, NM 87545. 


\section{Introduction}

Since it was developed by H.L. Eiselstein (1), more has been published about Inconel ${ }^{\circledR}$ alloy 718 then any other superalloy composition. Nevertheless, current advances in the examination of alloy structures continue to permit the definition of an improved level of understanding of this complex alloy, which is strengthened by the formation two precipitates (2): a body centered tetragonal $(a=0.3624 \mathrm{~nm}, c=0.7476 \mathrm{~nm}), D_{22}$ that in current terminology is referred to as gamma double prime $\left(\gamma^{\prime}\right)$, and a $\mathrm{L}_{2}$ precipitate ${ }^{(3)}(\mathrm{a}=0.3605 \mathrm{~nm})$, commonly termed gamma prime $\left(\gamma^{\prime}\right)$. Delta, an ordered orthorhombic (4) $\mathrm{DO}_{\mathrm{a}}(\mathrm{a}=0.5141 \mathrm{~nm}, \mathrm{~b}=0.4231 \mathrm{~nm}$, and $\mathrm{c}=0.4534 \mathrm{~nm})$ phase with a solvus of $1020^{\circ} \mathrm{C}\left(1870^{\circ} \mathrm{F}\right)(5)$ and a $\mathrm{MC}$ constituent $(\mathrm{a}=0.443 \mathrm{~nm})$ are the other phases normally present in the fully heat treated condition.

Originally, the heat treatment of alloy 718 started with a solution anneal at 1038 to $1065^{\circ} \mathrm{C}$ ( 1900 to $1950^{\circ} \mathrm{F}$ ), well above the delta solvus. This resulted in large grain sizes and denuded grain boundaries, the latter leading to poor notched stress rupture properties ${ }^{(6)}$. The current and preferred practice is to assure the presence of delta and $\mathrm{MC}$ by using a sub delta solvus anneal in the range of 930 to $1000{ }^{\circ} \mathrm{C}\left(1700\right.$ to $\left.1830^{\circ} \mathrm{F}\right)$ thus decorating the grain boundaries and preventing excessive grain growth. The more modern processing practices usually include some simultaneous sub - solvus final working and, in the case of direct aged (DA) material (7), there is no post working solution anneal. These steps establish the grain size and level of warm work. Subsequently, the alloy is aged in the temperature range of 590 to $760^{\circ} \mathrm{C}\left(1100\right.$ to $\left.1400^{\circ} \mathrm{F}\right)$ so as to precipitate the two strengthening phases : $\gamma^{\prime}$ and $\gamma^{\prime \prime}$.

In the practical application of any high temperature alloy, the retention of properties during prolonged elevated temperature service, and the associated structural changes during exposure, have always been a focus of metallurgical attention. This paper revisits these questions by examining the same materials as were used in the two classic studies in the area of alloy 718 stability $(8,9)$ but using the more advanced techniques currently available.

\section{Experimental}

Two sets of materials were examined. The first originated from the 1970 Barker, Ross and Radavich study (8), where the specimens had been aged under stress. The second originated from the more recent Korth (9) program (Heat 2180-6-9458) where the aging had been performed in the absence of stress, for periods up to $50,000 \mathrm{hr}$ 's. Reference can be made to the original studies for the full chemical analyses, but all were well within the GE C50TF79 and AMS 5663 specifications. Both had basically the same C ( $0.05 \%)$ and B ( 0.003 to $0.004 \%)$ contents, but the heat used in the Barker et al study was higher in $\mathrm{Nb}+\mathrm{Ta}(5.31 \%)$ then the Korth ( $5.04 \%$ ) material, which, however, was higher in Ti ( $1.01 \%$ vs $0.76 \%)$.

The Barker et al matcrial was processed through air electric furnace and VAR, forged to a pancake and annealed at $582^{\circ} \mathrm{C}$, so as to achieve a predominantly ASTM 5 grain size, before aging for $8 \mathrm{hr}$ 's. at $718^{\circ} \mathrm{C}$, furnace cooling at $38^{\circ} \mathrm{C} / \mathrm{hr}$. to $621^{\circ} \mathrm{C}$, and holding for $8 \mathrm{hr}$ 's.

The Korth specimens all originated from VIM + ESR processing and working to 1.3 and $1.9 \mathrm{~cm}$ diameter bar stock. They were annealed at $954^{\circ} \mathrm{C}$ to a ASTM 7 grain size, and aged 8 $\mathrm{hr}$ 's at $718^{\circ} \mathrm{C}, \mathrm{FC}$ to $621{ }^{\circ} \mathrm{C}$ and held at this temperature to give a total aging time of $18 \mathrm{hr}$ 's.

All quantitative metallography was performed on specimens first polished through 600 grit $\mathrm{SiC}$ and then electropolished. The electropolishing and etching was performed on unmounted specimens (10), in two successive and automatically controlled operations. For both operations the electrolyte was $80 \% \mathrm{CH}_{3} \mathrm{OH}+20 \% \mathrm{HClO}_{4}$ operated at -50 to $-40{ }^{\circ} \mathrm{C}$. The electropolishing cycle lasted $30 \mathrm{sec}$. at 25 volts, immediately followed by etching for $3 \mathrm{sec}$. at 3.0 volts. For uniform results temperature control was critical. Before starting the electropolishing cycle, it was necessary to equilibrate the specimen to the electropolishing solution's temperature and to monitor it, so that the IR drop did not produce overheating. The above polishing times, that were established for $1.3 \mathrm{~cm}$ diameter specimens, were increased to $35 \mathrm{sec}$. for $1.9 \mathrm{~cm}$ diameter specimens and decreased to $20 \mathrm{sec}$. for $0.6 \mathrm{~cm}$ diameter. The etching conditions were not varied. 
To calibrate the preparation technique, surface force microscopy photographs were utilized. This procedure allows the generation of a three dimensional view of the structure. Since the MC phases were essentially not attacked, they served as markers of the original surface, permitting the calculation of the rate of electropolishing as about $13 \mathrm{~nm} / \mathrm{sec}$. Figure 1 presents the $\gamma^{\prime}$ and $y^{\prime \prime}$ structure as revealed by the computer assisted enhancement of a surface force microscopy image. Examination of such images, lead to the conclusion that the preparation technique effectively reveals the diameter of the precipitates, but not their volume. Measurements of the precipitates in Figure 1 indicates that the $\gamma^{\prime}$ cuboids averaged about $0.05 \mu \mathrm{m}$ in diameter and $0.01 \mu \mathrm{m}$ in height, while the $\gamma^{\prime \prime}$ disks were some $0.1 \mu \mathrm{m}$ diameter and $0.025 \mu \mathrm{m}$ thick, standing an average of $0.012 \mu \mathrm{m}$ above the peaks of the $\gamma^{\prime}$ phases.
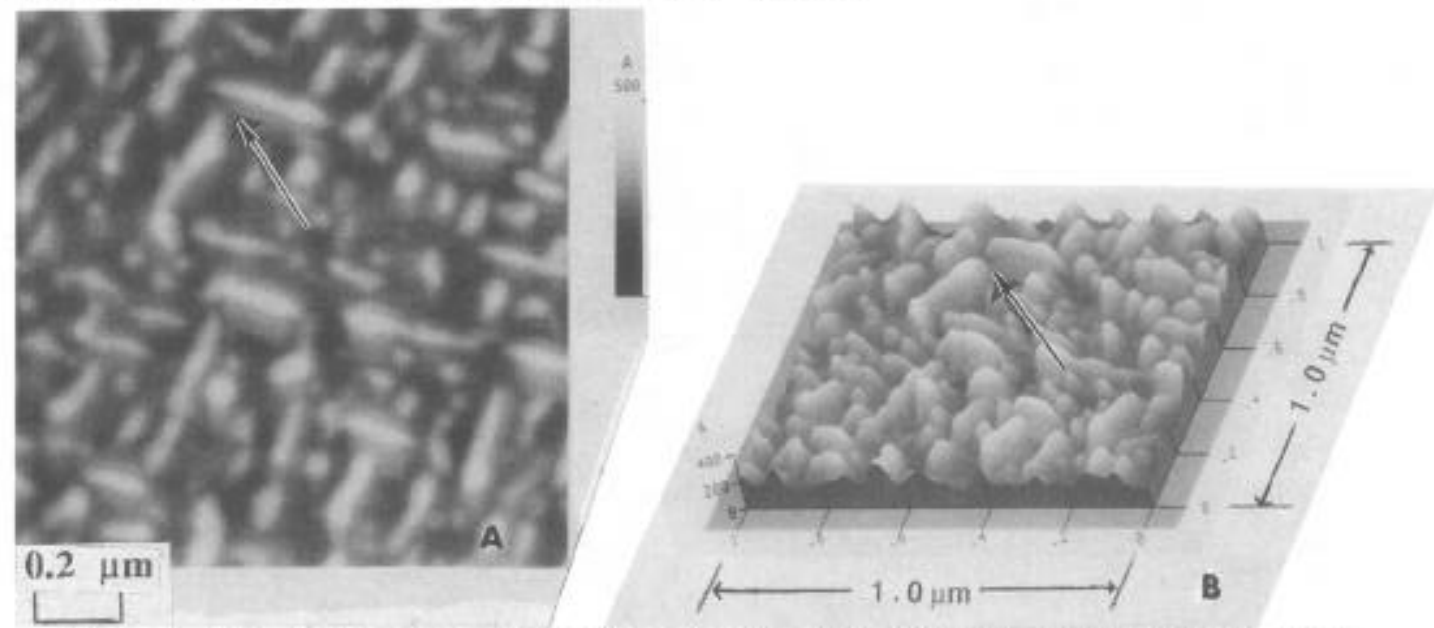

Figure 1. Atomic force microscopy view documenting effect of preparation technique in revealing the $\gamma^{\prime}$ and $\gamma^{\prime}$ ' structure in an alloy 718 disk after 23,000 hr's service.

A. Plan view . B.Three dimensional view. Arrow indicates point of coincidence in A.and B.

\section{Results of Image Analysis}

For purposes of record, Figure 2 illustrates the microstructure of a specimen, that had been aged with no stress for $50,000 \mathrm{hr}$ 's at $649^{\circ} \mathrm{C}$, when viewed in a field emission SEM. All image analysis was restricted to the $\gamma^{\prime}$ and $\gamma^{\prime \prime}$ phases, prepared for examination by electropolishing and etching in metholic - perchloric. Although the rates of growth of the other phases, including delta, were too variable to quantify and usually too difficult to differentiate, some general comments can be made. Little if any growth of delta occurs at $538^{\circ} \mathrm{C}$. At higher temperatures the delta plates begin to grow and at $704{ }^{\circ} \mathrm{C}$ the delta plates will have extended completely across the grain diameter. Alpha $\mathrm{Cr}$ is present whenever there is delta. We have even identified 0.02 $\mu \mathrm{m} \alpha-\mathrm{Cr}$ in as heat treated specimens, particularly in direct aged (DA) material.
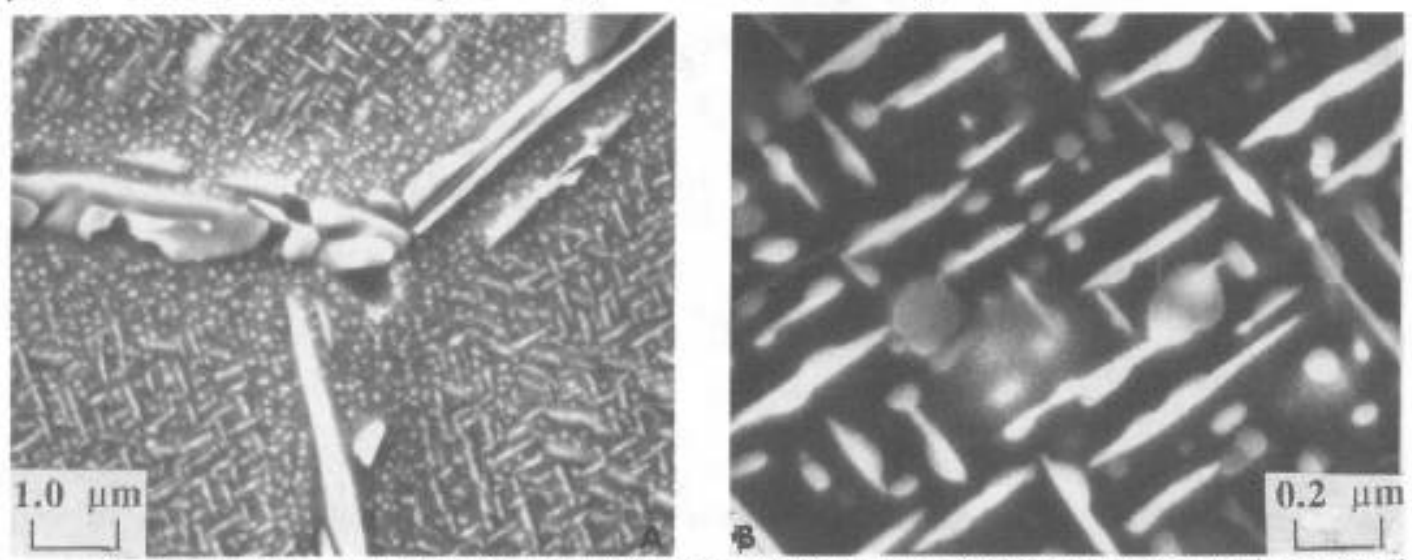

Figure 2. Microstructure of alloy 718 aged 50,000 hr's at $649^{\circ} \mathrm{C}$ as prepared in metholic perchloric and viewed in a high resolution, field emission SEM. Compare to Figure 1. 
The $\gamma^{\prime}$ and $\gamma^{\prime \prime}$ particle diameters were measured by examining the electropolished specimens in a field emission SEM. At least six different areas were photographed in each specimen, always in the center of a different grain, with the field of view selected so as to be removed from any delta plates. About 100 different particles were physically measured, on photographs, in each determination. The particle diameters, including the one sigma variation, are recorded in Table I. As it became obvious that the results could be related through the standard Larsen Miller parameter $P={ }^{\circ} \mathrm{K}(25+\log t)$, where $t$ is the aging time in hr's., the data are summarized in the order of this parameter. All exposures under stress in Table I are from Barker et al ${ }^{(8)}$ study.

'Table 1. Summary of Measurement of $\gamma$ 'and $\gamma$ " Particle Size.

$\begin{array}{cccccc}\begin{array}{c}\text { Temp. } \\ { }_{\mathrm{C}}\end{array} & \begin{array}{c}\text { Stress } \\ \mathrm{MPa}\end{array} & \begin{array}{c}\text { Time } \\ \text { Hours }\end{array} & \begin{array}{c}\mathrm{P} \\ { }^{\circ} \mathrm{K}(25+\log ) \\ \times 10^{-3}\end{array} & \begin{array}{c}\mathrm{D}^{\prime},{ }^{\prime}, \pm \sigma \\ \mu \mathrm{m}\end{array} & \begin{array}{c}\mathrm{D}^{\prime \prime}, \gamma^{\prime \prime}, \pm \sigma \\ \mu \mathrm{m}\end{array} \\ 593 & 648 & 10606 & 25.14 & 0.015 \pm 0.005 & 0.066 \pm 0.02 \\ 593 & 0 & 25000 & 25.46 & - & 0.065 \pm 0.02 \\ 593 & 590 & 33991 & 25.57 & 0.026 \pm 0.008 & 0.082 \pm 0.03 \\ 649 & 600 & 747 & 25.70 & 0.022 \pm 0.005 & 0.078 \pm 0.03 \\ 593 & 0 & 50000 & 25.72 & 0.024 \pm 0.007 & 0.076 \pm 0.03 \\ 649 & 537 & 3132 & 26.27 & 0.031 \pm 0.009 & 0.120 \pm 0.05 \\ 649 & 537 & 3830 & 26.35 & 0.031 \pm 0.010 & 0.105 \pm 0.04 \\ 621 & 0 & 50000 & 26.70 & 0.034 \pm 0.010 & 0.132 \pm 0.03 \\ 649 & 469 & 7262 & 26.61 & 0.038 \pm 0.012 & 0.183 \pm 0.08 \\ 649 & 0 & 10000 & 26.74 & 0.039 \pm 0.013 & 0.163 \pm 0.07 \\ 649 & 434 & 10233 & 26.75 & 0.035 \pm 0.010 & 0.176 \pm 0.07 \\ 649 & 0 & 25000 & 27.10 & 0.048 \pm 0.014 & 0.227 \pm 0.07 \\ 649 & 0 & 50000 & 27.38 & 0.061 \pm 0.018 & 0.289 \pm 0.12 \\ 704 & 255 & 6048 & 28.12 & 0.068 \pm 0.022 & 0.409 \pm 0.19\end{array}$

There was no opportunity to examine these materials in the as received condition. For purpose of comparison, however, the as heat treated sizes of the $\gamma^{\prime}$ and $\gamma^{\prime \prime}$ are typically in the range of $0.01 \mu \mathrm{m}$ for $\gamma^{\prime}$ and $0.02 \mu \mathrm{m}$ for $\gamma^{\prime \prime}$ for the type of heat treatment originally used on these samples.

The relationship between the Larsen - Miller parameter $P$ and the average precipitate size, is plotted in Figure 3 and indicates that the role of stress, as well as the chemistry and processing variations that differentiated the Barker et al ${ }^{(8)}$ and Korth ${ }^{(9)}$ materials, can be ignored.

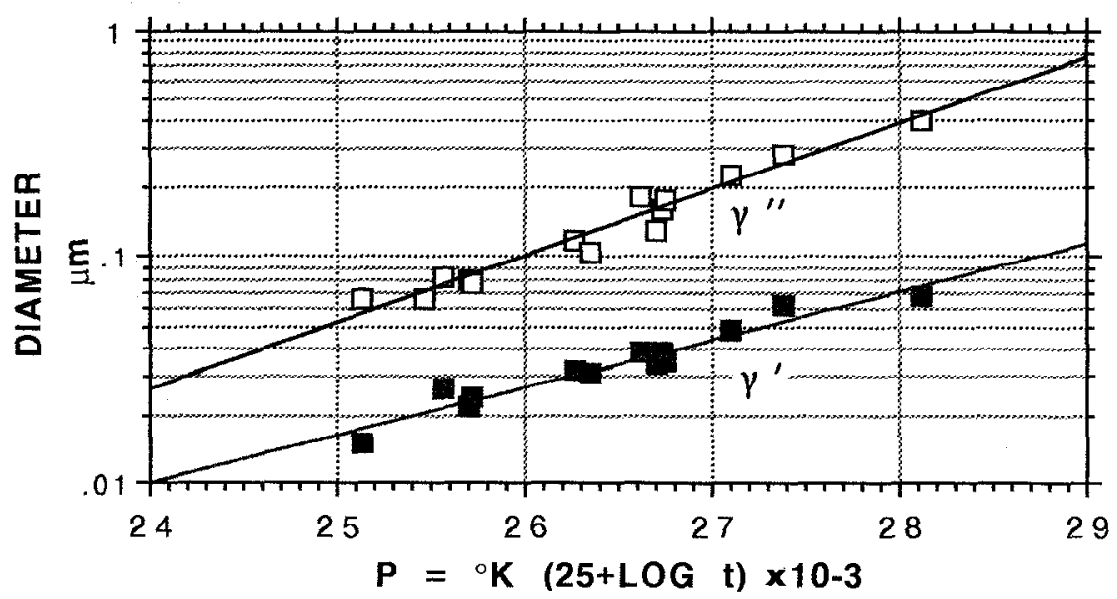

Figure 3.Relationship between precipitate diameter and the exposure parameter P.

The lack of any large differences in $\gamma^{\prime}$ and $\gamma^{\prime \prime}$ growth kinetics between the two sets of data allows the formulation of the regression equations ignoring the effect of stress and variations in 
chemistry and processing that existed between the two sets of specimens. It is then possible to relate the precipitate diameter ( $\mathrm{D}$ in $\mu \mathrm{m}$ ) to the exposure parameter $\mathrm{P}={ }^{\circ} \mathrm{K}(25+\log \mathrm{t})$ :

$$
\begin{array}{lll}
\text { for } \gamma^{\prime}, & \log P=\frac{\log D^{\prime}+7.1158}{0.21314} & R^{2}=0.94
\end{array}
$$

Similarly, it is possible to relate the post exposure mechanical properties measured in the original studies $(8,9)$ to the $\gamma^{\prime \prime}$ size produced by any aging condition. For example, Figure 4 shows the relationship between $\gamma^{\prime \prime}$ diameter and the 25 and $649{ }^{\circ} \mathrm{C}, 0.2 \%$ Yield strength measured for the same exposure condition.

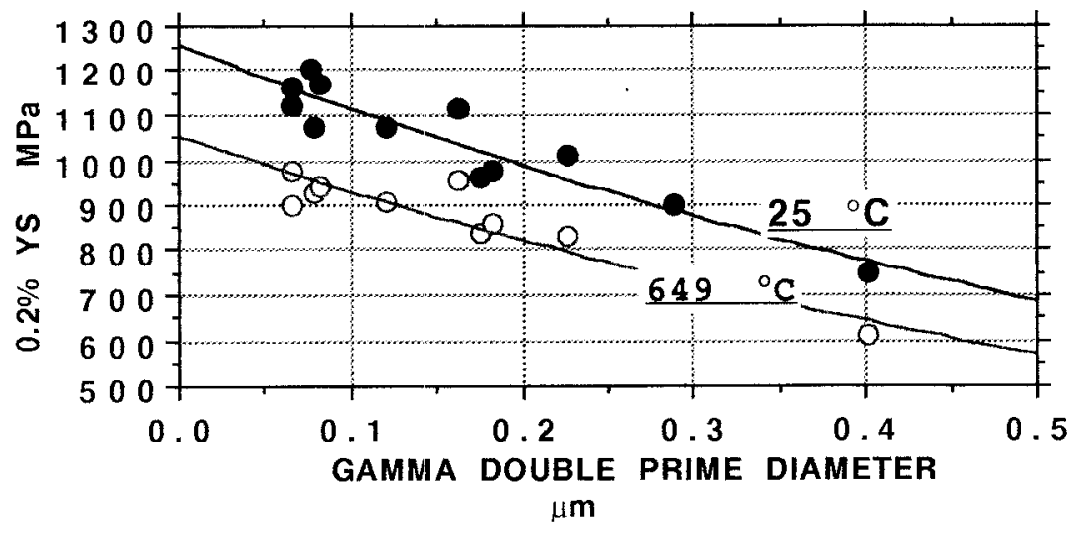

Figure 4. Relationship between $\gamma^{\prime \prime}$ size and $0.2 \%$ Yield Strength after exposure.

The dependence of the 25 and $649^{\circ} \mathrm{C} 0.2 \% \mathrm{YS}$, on the average $\gamma^{\prime \prime}$ precipitate diameter, can be described by the following regression equations:

$$
\begin{array}{llll}
\text { At } 25^{\circ} \mathrm{C}, & \log (0.2 \% \text { YS }) 25^{\circ} \mathrm{C}=3.0995-0.52479\left(\mathrm{D}^{\prime \prime}\right), & \mathrm{R}^{2}=0.89 & \# 3 \\
\text { At } 649^{\circ} \mathrm{C}, & \log (0.2 \% \text { YS }) 649^{\circ} \mathrm{C}=3.0221-0.53497\left(\mathrm{D}^{\prime \prime}\right), & \mathrm{R}^{2}=0.87 & \# 4
\end{array}
$$

Attempts to establish similar relationships to the average $\gamma^{\prime}$ size produced regression equations that could fit only some $70 \%$ of the data, while equations 3 and 4 , which are based on the average $y^{\prime}$ diameter, can account for some $87 \%$ of the data.

\section{Analytical Electron Microscopy}

All structural studies were restricted largely to the material aged $50,000 \mathrm{hr}$ 's. at $649{ }^{\circ} \mathrm{C}$, in the absence of stress, that originated from the Korth study (9). Standard preparation and examination procedures were used. These were backed up by the SEM examination, including energy dispersive $x$-ray analysis, of all specimens with the aim of verifying that the 50,000 hr's $1649^{\circ} \mathrm{C}$ specimen was generally representative, with respect to the identity and morphology of the phases, in the other specimens studied here.

As shown in Figure 5, dark and bright field TEM examination was utilizcd to verify the SEM preparation techniques used for image analysis, and to verify the major phases present, after such prolonged exposure. 

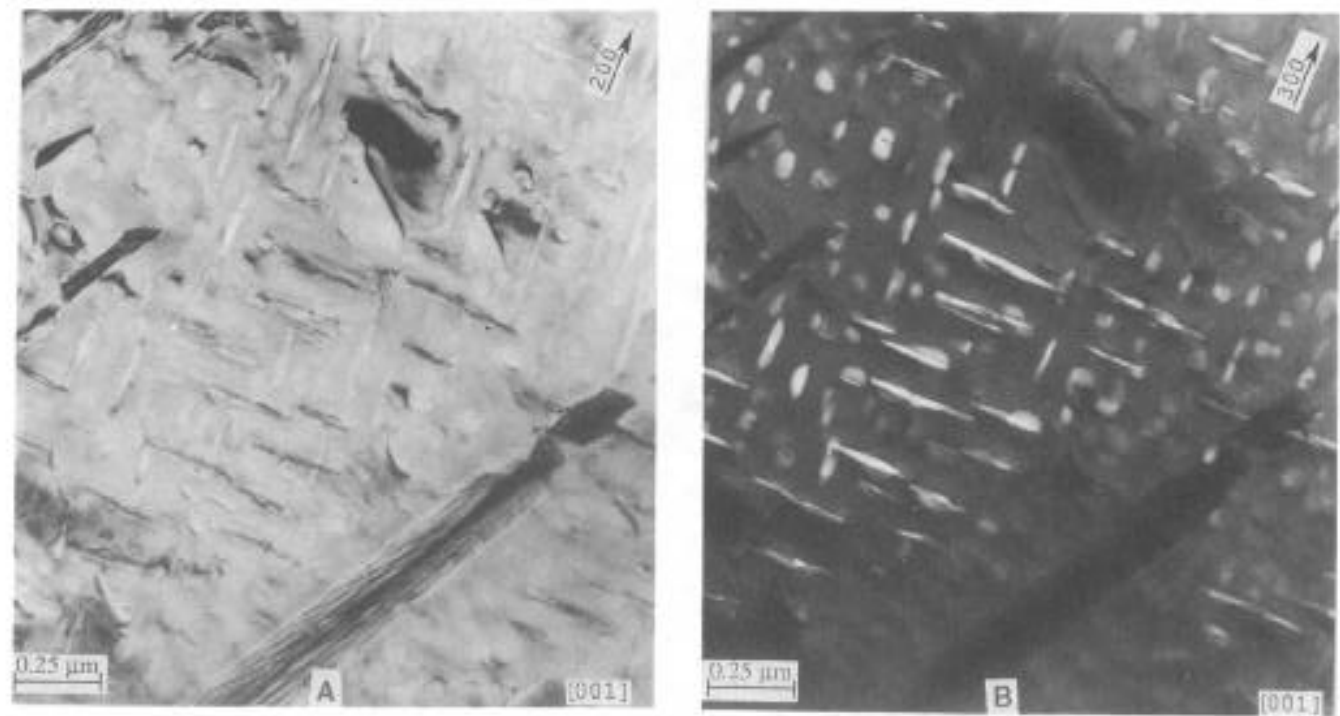

Figure 5. Delta plates enclosing $\gamma^{\prime}\left(\mathrm{Ll}_{2}\right)$ and $\gamma^{\prime \prime}\left(\mathrm{DO}_{22}\right)$ precipitates observed in the $50,000 \mathrm{hr}$ 's. $/ 649^{\circ} \mathrm{C}$ specimen. A. Bright field, compare to SEM images in Figure 2 B. Dark field, clearly identifying the $\mathrm{Ll}_{2}$ and one variant of the $\mathrm{DO}_{22}$ precipitates.

Figure 6 illustrates a more heterogeneous part of the same specimen, where $\alpha \mathrm{Cr}$, sigma and Laves have all formed in an area of heavy delta plate concentration, usually nucleating on the delta plates. This morphology was typical for these minor constituents, particularly for $\alpha \mathrm{Cr}$ and sigma. These phases always nucleated on the surface of an advancing delta plate. The growth of the $\mathrm{Ni} 3 \mathrm{Nb}$, ordered $\mathrm{DO}_{\mathrm{a}}$, delta is driven by the solution of the $\mathrm{Ni} 3(\mathrm{Nb}, \mathrm{Al}, \mathrm{Ti}), \gamma^{\prime \prime}$, and the resultant enrichment of the matrix in niobium. Examination of the matrix areas of Figure 6 clearly illustrate this mechanism. The matrix areas adjacent to heavy concentrations of delta are

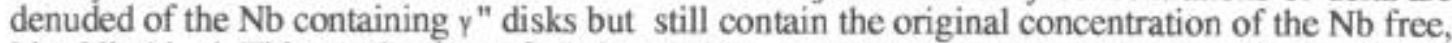
$L_{2}, \mathrm{Ni} 3 \mathrm{Al}, \gamma^{\prime}$. This mechanism of $\gamma^{\prime \prime}$ denudation can also observed next to the delta plates in Figure $2 \mathrm{~A}$ and the upper left hand corner of Figure 5.

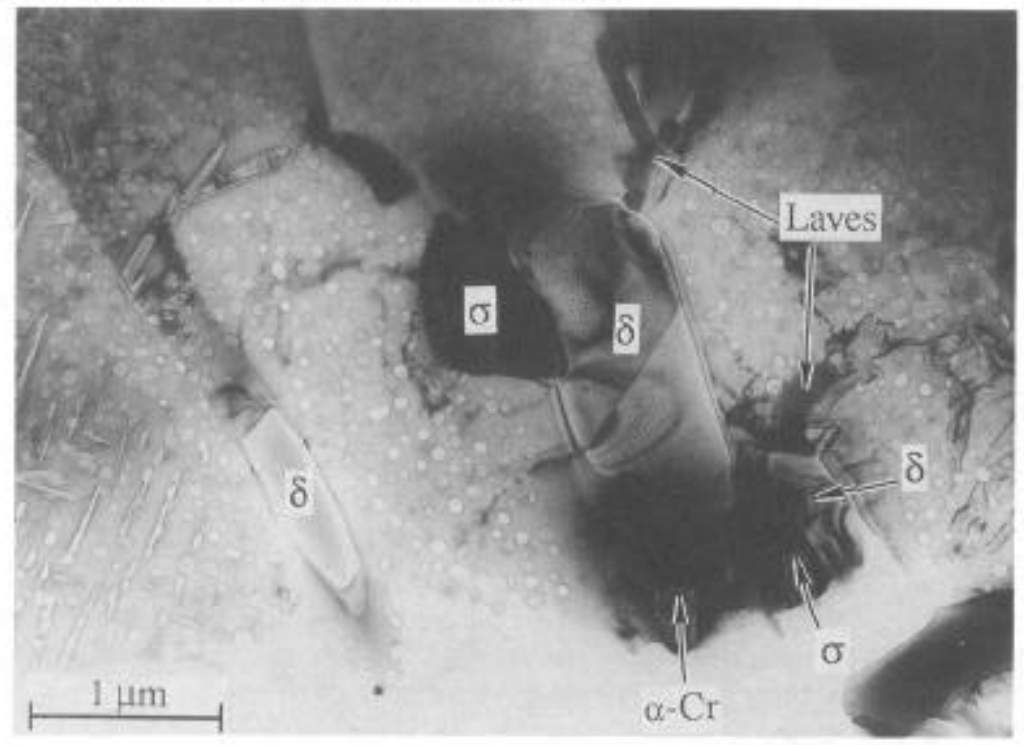

Figure 6. Intragranular precipitates of delta with $\alpha \mathrm{Cr}$, sigma ( $\sigma$ ), and Laves nucleating on the delta plates. The delta plates had themselves nucleated on a MC particle. Note the absence of $y^{\prime \prime}$ and the presence of $\gamma^{\prime}$ adjacent to the delta plates. See Figure 7. 
Phase identification was achieved through the application of analytical electron microscopy (AEM) procedures, applied in TEM, including: selected area diffraction ( SAD ), convergent beam electron diffraction ( CBED) and energy dispersive $\mathrm{x}$ - ray analysis . Figure 7 illustrates typical results that were obtained on the application of these procedures to the area depicted in Figure 6.
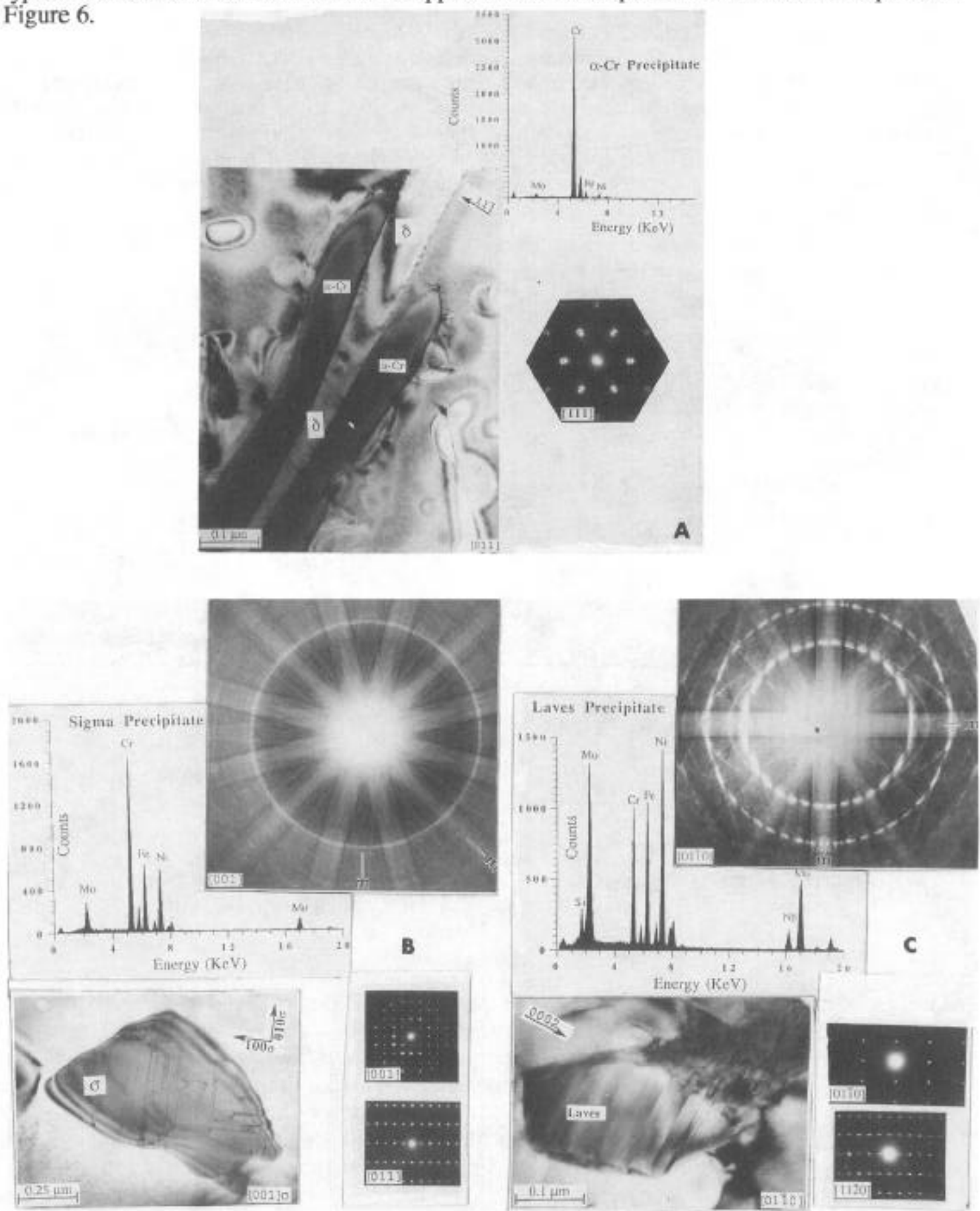

Figure 7. AEM phase identification of minor phases in Figure 6, showing SAD and CBED patterns, as well as energy dispersive $\mathrm{x}$-ray spectra.

A Intragranular delta plate surrounded completely by $\alpha \mathrm{Cr}$.

B Sigma phase with faulting along $\{100\}$ planes.

C. Laves phase with faulting on (0001) planes. Note Si level. 
In addition to the phases identified in Figure 7, only some MC constituents were observed. No secondary carbides, or borides, were identified the morphology of the MC and Laves phases was different from that of the $\alpha \mathrm{Cr}$ and sigma. While the latter two constituents were nearly always nucleated on delta plates, the MC and Laves phases, whether in intragranular or grain boundary positions, had largely formed above the delta solvus. Usually delta plates had nucleated on the prior MC and Laves particles.

Even after the $50,000 / 649^{\circ} \mathrm{C}$ exposure to which this material was subjected, there was little tendency to form continuous grain boundary films, except by delta. The delta precipitates, at grain boundaries were, at high magnification often revealed to be not completely continuous Figure $8 \mathrm{~A}$ illustrates typical grain boundaries. Figure $8 \mathrm{~B}$ an exception to the generalization that continuous grain boundary films did not form. A continuous grain boundary film of Laves, which did not extend more then a fraction of one grain diameter, was observed in one part of the $50,000 \mathrm{hr} ' \mathrm{~s} . / 649^{\circ} \mathrm{C}$ specimen.
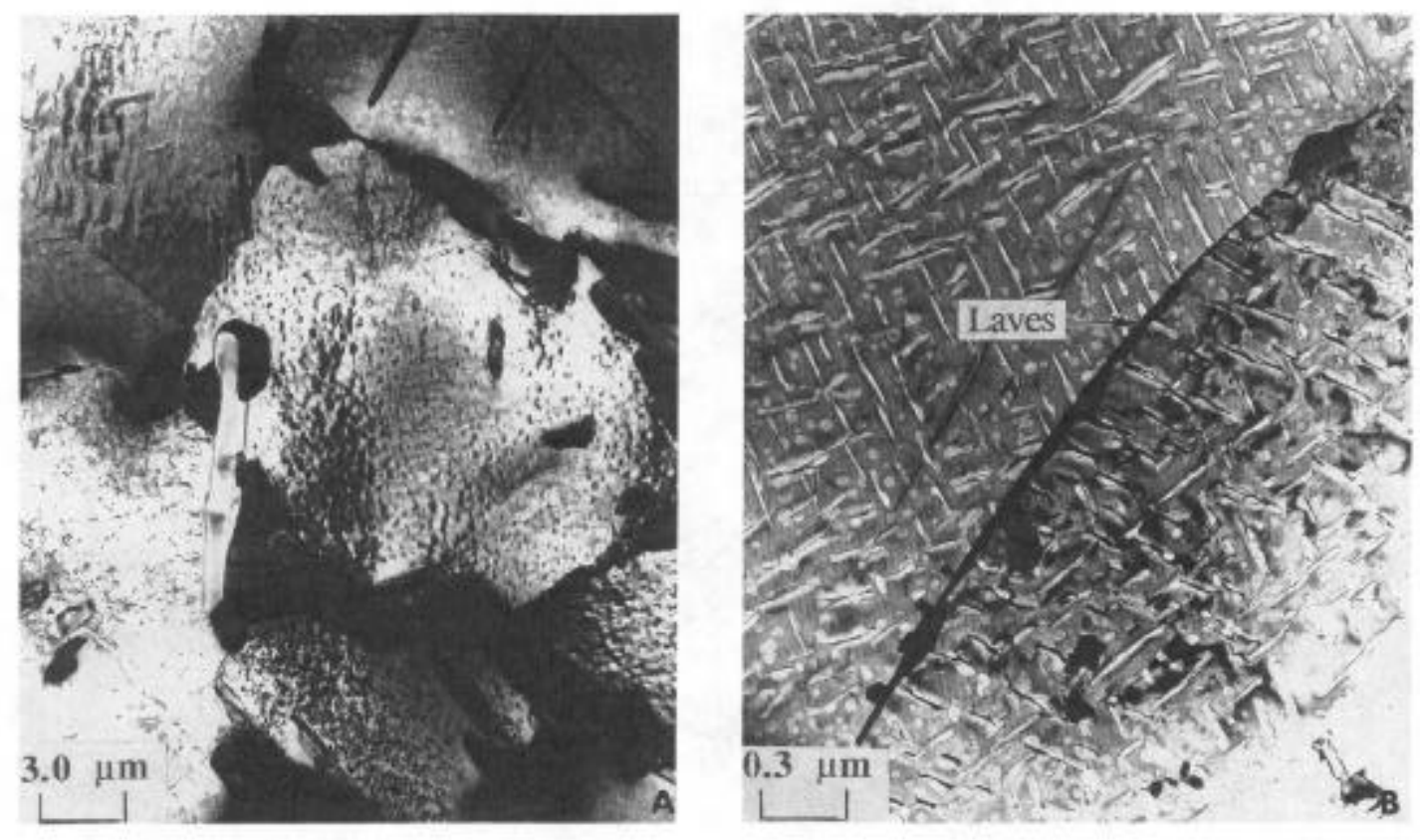

Figure 8. Grain boundary structures in alloy 718 after $50,000 \mathrm{hr}$ 's. at $649^{\circ} \mathrm{C}$.

A. Typical view. B. Grain boundary Laves film.

\section{Discussion}

The development of our understanding of the metallurgy of alloy 718 is an interesting series of advances. Eiselstein (1 ) correctly identified the presence of MC, Laves, and delta, but believed that the main strengthening precipitate was $\gamma^{\prime}$ and that $\mathrm{M}_{6} \mathrm{C}$ was a major grain boundary constituent. Only in 1968, with the availability of TEM, were the main strengthening phases identified as $y^{\prime}+\gamma^{\prime \prime}(2,3)$. In their study of the effects of long time exposure on alloy 718 , Barker et al. ( 8 ) identified the precipitation of delta, sigma, and Laves, as the main structural changes that occur on prolonged exposure. In their classic summary of the investigations of


$\mathrm{mu}$ as the phases that were identified in wrought 718 . The Committee did not find any other carbides or borides (11), nor did Barker et al. (8) in their original study of the same material examined here. In the Barker et al. study a diffraction pattern was given that included four 


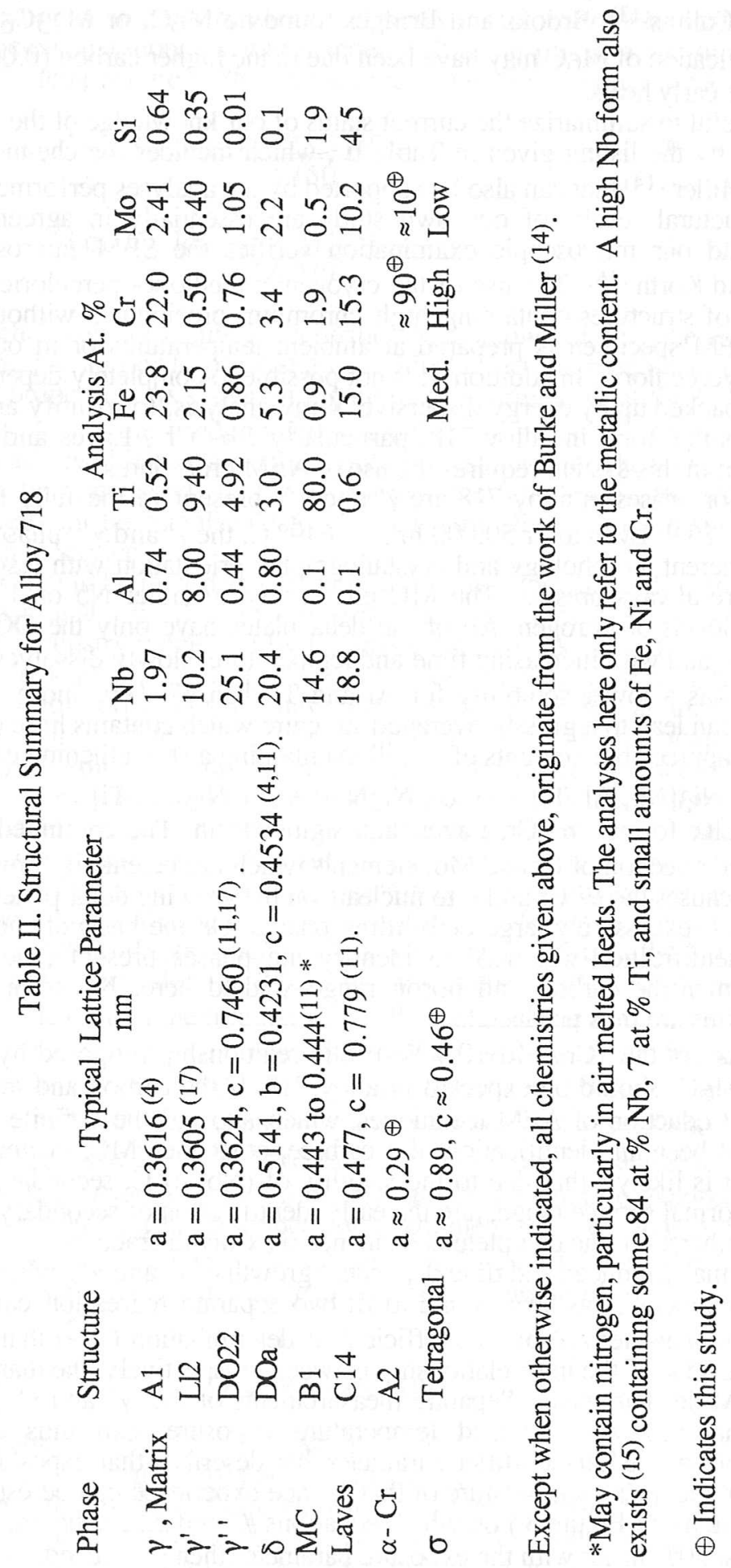


reflections that were identified as bcc and can be indexed to a lattice where $a \approx 0.29 \mathrm{~nm}$. These reflections were referred to by the authors as $\alpha^{1}$ but probably were the first identification of $\alpha$ $\mathrm{Cr}$ (8). The first mention in the open literature of the presence of $\alpha \mathrm{Cr}$, after prolonged exposure, was made by Brooks and Bridges (12), but no crystallographic data were given. Similar to Collins ${ }^{(13)}$, Brooks and Bridges found no $\mathrm{M}_{6} \mathrm{C}$, or $\mathrm{M}_{23} \mathrm{C}_{6}$, pointing out that the early identification of $\mathrm{M}_{6} \mathrm{C}$ may have been due to the higher carbon $(0.06 \%)^{(1)}$, and air melted nature of the early heats.

It is useful to summarize the current status of our knowledge of the structural characteristics of alloy 718 by the listing given in Table II , which includes the chemical analyses reported by Burke and Miller (14) that can also be supported by the analyses performed by Cieslak et al. (15).

The structural results of our own study are essentially in agreement with the Table II summary and our microscopic examination verifies the SEM microstructures published by Radavich and Korth (16). The use of the cryogenic, metholic- perchloric electrolytes, allows the preparation of structures containing high chromium precipitates without their loss, as occurs when the SEM specimen is prepared at ambient temperatures or in other electrolytes such as metholic- hydrochloric. In addition, it is not possible to completely depend on SEM examination even when backed up by energy dispersive X-ray analysis, to identify and differentiate between many phases that form in alloy 718, particularly : $\alpha-\mathrm{Cr}$, Laves and sigma. Accurate phase identification in this system requires the use of AEM procedures.

The major phases in alloy 718 are $\gamma^{\prime}$ and $\gamma^{\prime \prime}$, present in the fully heat treated condition at about $19 \mathrm{wt} \%{ }^{(3)}$. Even after $50,000 \mathrm{hr}$ 's at $649^{\circ} \mathrm{C}$, the $\gamma^{\prime}$ and $\gamma^{\prime \prime}$ phases are still present, with the same coherent morphology and crystallographic orientation with respect to the matrix. Delta and MC's are always present. The MC phase may be either $\mathrm{Nb}$ or Ti rich, and may contain appreciable levels of nitrogen. All of the delta plates have only the $\mathrm{DO}_{\mathrm{a}}$ structure. As the $\gamma^{\prime \prime}$ phase grows, and with increasing time and temperature, slowly dissolves, it is replaced by delta. Since delta has a lower solubility for $\mathrm{Al}$ and Ti than $\gamma^{\prime \prime}$ (14), more $\gamma^{\prime}$ is precipitated. This mechanism can lead to a grossly overaged structure which contains little $\gamma^{\prime \prime}$, predominantly delta plates, with appreciable amounts of $\gamma^{\prime}$ still maintaining a strengthening contribution. Essentially,

$$
\gamma^{\prime \prime}\left(\mathrm{Ni} 3[\mathrm{Nb}, \mathrm{Al}, \mathrm{Til}) \rightarrow \delta(\mathrm{Ni3Nb})+\gamma^{\prime}(\mathrm{Ni}\lceil\text { [Al, Til })\right.
$$

As more delta forms, $\alpha$ - Cr, Laves, and sigma form. The continued growth of delta causes the continued rejection of $\mathrm{Cr}$ and Mo, elements which are essentially imiscible in delta (14). This mechanism causes the $\alpha$ - $\mathrm{Cr}$ and $\sigma$ to nucleate on the growing delta plates, possibly retarding the formation of excessively large embrittling phases. On the basis of most investigations where structural identification was used to identify the phases present, no secondary carbides or borides form in the carbon and boron range studied here. No completely continuous grain boundary films are thus produced.

On the basis of the $(\mathrm{Cr} / \mathrm{Mo}+0.4 \mathrm{~W})$ ratio relationship proposed by Dreshfield(18), $\mathrm{M}_{23} \mathrm{C}_{6}$ rather then $\mathrm{M}_{6} \mathrm{C}$ should be expected in alloy 718 , if the carbon and nitrogen are high enough. Since the introduction of AEM techniques, which allowed the definite identification of $\alpha-\mathrm{Cr}$, there has not been an identification of a carbide, other then $\mathrm{MC}$, in normal chemistry wrought alloy 718. It is likely, that due to the stability of $(\mathrm{Nb}, \mathrm{Ti}) \mathrm{C}$, secondary carbides do not form, within the normal service range, and the early identification of secondary carbides was due to the limitations inherent in the complete dependence on $\mathrm{x}$-ray diffraction.

The thermally induced and time dependent growth of $\gamma^{\prime}$ and $\gamma^{\prime \prime}$, when measured in carefully prepared specimens, has been found to fit two separate regression equations. Both equations \#1and \#2 are characterized by a coefficient of determination $\left(\mathrm{R}^{2}\right)$ that indicates that they can predict some $95 \%$ of the interrelationship between, respectively, the diameter of $\gamma^{\prime}$ and $\gamma^{\prime \prime}$, and the Larsen Miller Parameter. Separate measurements of the $\gamma^{\prime}$ and $\gamma^{\prime \prime}$ precipitates in an alloy 718 part that has seen elevated temperature exposure, can thus allow two independent determinations of the Larsen Miller Parameter that describes that exposure. If the service time is known, then the mean temperature of that service experience can be estimated. As indicated by the plot of the data (Figure 3 ) on which equations \#1 and \#2 are based, the diameter of the $\gamma^{\prime \prime}$ varies almost $50 \%$ faster with the exposure parameter then $\gamma^{\prime}$. Indeed, the $\gamma^{\prime}$ ' precipitates show a five fold variation in the exposure range studied here, and are always larger then the $\gamma^{\prime}$. The $\gamma^{\prime}$ ' phases are thus easier to measure and more sensitive to parameter changes. These equations are believed to be valid over a parameter range in SI units of about 24 to $29 \times 10^{3}$. 
For $1000 \mathrm{hr}$ 's. cxposures this covers a tempcrature range of 580 to $760^{\circ} \mathrm{C}$, and 555 to $730^{\circ} \mathrm{C}$ for 10,000 hr's. exposure. Essentially, these equations are restricted to a temperature range that is largely in excess of the normal temperature range of alloy 718 application but, they thus are very useful to indicate cases of over temperature in long term service parts whose failure mechanism must be ascertained.

For ease of application in an industry which still relies on the Fahrenheit scale, equations \#1 and $\# 2$ are rewritten below in a more suitable manner, still using $\mu \mathrm{m}$ as a measure of precipitate diamcter $\mathrm{D}$ but with the temperature in ${ }^{\circ} \mathrm{R}$ and the time $(t)$ in hr's., where $P-{ }^{\circ} R(25+\log t)$ :

$$
\begin{aligned}
& \text { for } \gamma^{\prime}, \quad \quad \log P=\frac{\log D^{\prime}+23.53496}{13.150} \quad \mathbf{R}^{2}=0.96 \quad \# 6 \\
& \text { for } \gamma^{\prime \prime}, \quad \quad \log P=\frac{\log D^{\prime \prime}+31.12384}{18.039} \quad R^{2}=0.95 \quad \# 7
\end{aligned}
$$

The measuring techniques for $\gamma^{\prime}$ and $\gamma^{\prime \prime}$ described here allow not only the estimation of the parameter of exposure, but appear to provide a quantification of the precipitate size that can be related to mechanical properties. As shown in Figure 4, the correlation of the $0.2 \%$ YS, at both 25 and $649^{\circ} \mathrm{C}$, is best to $\gamma^{\prime \prime}$, the predominant strengthening phase (3). Obviously , a better relationship could be achieved if a relationship could be established where the contribution of both precipitates can be considered. In the meantime, the simplified relationship given in equations 3 and 4 , that can be established to $y "$, can still be useful in estimating residual properties after long time service.

In brief, alloy 718 should be regarded as a stable alloy, that does not suffer from unexpected reductions in load bearing ability during service in it's normal temperature range. It does not, when produced in the chemistry range and by the processing routes currently used, suffer from any gross embrittling reactions. Due to the great stability of the $\mathrm{Nb}$ containing monocarbide, secondary carbides do not form. Borides have never been identified at the B content now common to the wrought form. The $\alpha-\mathrm{Cr}$, Laves and sigma that do precipitate, on prolonged exposure, appear to be the direct result of delta growth. Chromium is essentially imiscible in delta and as the delta plates grow, $\mathrm{Cr}$ is rejected into the matrix. This mechanism assures that the precipitation of these constituents is not continuous, but intermittent, occurring only when the level of the required solutes has built up to a sufficient concentration to permit their nucleation. Almost by definition, once the $\alpha-\mathrm{Cr}$, Laves and sigma phases precipitate, their growth stops, at least until a new supersaturation of $\mathrm{Cr}$ can be established. The properties of alloy 718 are degraded only by the growth and subsequent solution of $\gamma$ " that provides the $\mathrm{Nb}$ flux that feeds delta formation. Excessive formation of delta in time reduces ambient temperature Charpy impact properties to some $65 \%$ of the original value ${ }^{(10)}$ for exposure conditions equivalent to a Larsen - Miller parameter of $24.8 \times 10^{3}$. Nevertheless, after exposure for the equivalent of an exposure parameter of almost $27.4 \times 10^{3}$ the Charpy impact is at $20 \%$ of the as heat treated level, about 8.8 joules ${ }^{(9)}$. Most other properties are much less sensitive. Exposures equivalent to exposure parameters of about $27.0 \times 10^{3}$ are required to produce any appreciable reduction in 25 or $649^{\circ} \mathrm{C} 0.2 \%$ Yield Strength $(8,16)$. Alloy 718 should thus not be exposed to conditions of time and temperature that can be described by a parameter that exceeds a value of some $25 \times 10^{3}$, but this would be well above the temperature range of alloy 718 in conventional turbine applications. In the temperature range of it's normal usage alloy 718 is an extremely stable composition.

\section{Acknowledgments}

We are greatly indebted to Professor J. F. Radavich of Purdue University for providing the specimens from the Barker et al 1970 study, and to Dr.G.E. Korth of the Idaho National Engineering Laboratory, for providing material from his long term exposures. Dr. W.G. Morris, of the General Electric Co. Central Research and Development Laboratory performed the SFM examination. We appreciate the permission from the management of the Engineering Materials Technology Laboratory, GE Aircraft Engines to publish this paper.

${ }^{\circledR}$ Inconel is a registered trade mark of the International Nickel Co. 


\section{$\underline{\text { References }}$}

1. H.L.Eiselstein, "Metallurgy of a Columbium-Hardened Ni-Cr-Fe Alloy" , Special Publication STP 369, Advances in The Technology of Stainless Steels, ASTM, (1965), p.62.

2. P.S. Kotval, " Identification of the Strengthening Phase in Inconel Alloy 718", Trans. AIME , (1968), 242, p. 1764.

3. D. F. Paulonis, J. M. Oblak and D.S. Duval, "Precipitation in Nickel - Base Alloy 718", Trans ASM. (1969), 62, p. 611.

4. M Sundararaman, P. Mukhopadhyay and S. Banarjee, "Precipitation of the $\delta-\mathrm{Niz} \mathrm{Nb}$ phase in Two Nickel Base Alloys", Met. Trans. A (1988), 19A p. 453.

5. E.E. Brown and D.R. Muzyka, " Nickel - Iron Alloys", Superalloys II. C.T. Sims, N. S. Stoloff, and W. C. Hagel, ed., John Wiley and Sons. (1987), Chapter 6, p. 165.

6. R.L. Raymond, " Effect of Grain Boundary Denudation of Gamma Prime on Notch Rupture Ductility of Ni - Cr Alloys X- 750 and 718 ", Trans. AIME, (1967), 239.p. 1415.

7. D.D. Krueger, "The Development of Direct Age 718 for Engine Disk Applications", Superalloy 718, Metallurgy and Applications, E.A. Loria ed., TMS, (1989), p.279.

8. J.F. Barker, E.W. Ross, and J.F.Radavich, " Long Time Stability of Inconel 718", J. of Metals, (1970), January, p. 31.

9. G. E. Korth, "Mechanical Properties Test Data of Alloy 718 for Liquid Metal Fast Breeder Reactor Applications", Report EGG-2229, US Department of Energy, (1983)

10. S.T. Wlodek, "SEM Metallography of Superalloys", Microstructural Science, T.A.Place et al. ed. ASM / IMS (1990), 18, p. 407.

11. M.J. Donachie and O.H. Kriege," Phase Extraction and Analysis in Superalloys-Summary of Investigations by ASTM Committee E 4 ", J.of Materials ,JMSLA, (1972),p.269..

12. J.W. Brooks and P.J. Bridges, "Metallurgical Stabillity of Inconel Alloy 718", Superalloys 1988, D.N. Duhl et al ed., Metallurgical Soc. Inc., (1988), p.33.

13. H.E. Collins, " Relative Long- Time Stability of Carbide and Intermetallic Phases in Nickel-Base Alloys", Trans. ASM ,(1969) p 62.

14. M.G. Burke and M.K.Miller, "Precipitation in Alloy 718, a Combined AEM and APFIM Investigation", Superalloy 718 and 625 and Various Derivatives", F.A. I oria ed., TMS, (1991), p. 337.

15. M.J. Cieslak et al., "The Solidification of Alloy 718 and other Nb Containing Alloys", Superalloy 718, Metallurgy and Applications, E.A. Loria ed., TMS, (1989), p.59.

16. J.F.Radavich and G.E. Korth, "High Temperature Degradation of Alloy 718 After Prolonged High Temperature Exposure", Superalloys 1992, S.D. Antolovich et al. ed.TMS (1992), p.497.

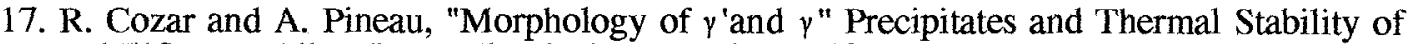
Inconel 718 Type Alloys", Metallurgical Transactions, (1973), 4, p.47.

18. R.L. Dreshfield, "The Effect of Refractory Elements on the Stability of Complex Carbides in Ni- Base Alloys", Trans.ASM, (1968), 61, p.352. 


\title{
ERRATUM
}

\section{THE EFFECTS OF LONG TIME EXPOSURE ON ALLOY 718}

\author{
S.T.Wlodek* and R.D.Field** \\ GE Aircraft Engines Cincinnati, $\mathrm{OH} 45215$
}

\footnotetext{
* Gamma Prime Consultants, San Diego, CA 92127-1272.

** Los Alamos National Laboratories, Los Alamos, NM 87545.
}

Equations 1 and 2, as originally published in the above paper (1) are in errò. The correct relationship between the diameter in $\mu \mathrm{m}$ of the $\mathrm{Ll} 2, \gamma^{\prime}$, and the $\mathrm{DO}_{22}, \gamma^{\prime \prime}$, phases and the Larsen-Miller parameter ( $\left.\mathrm{P}=\mathrm{T}[25+\log t] \times 10^{-3}\right)$ pertinent to the exposure that produced their growth, can be described by:

$$
\begin{array}{lll}
\text { for } \gamma^{\prime}, & \log P=\frac{\log D^{\prime}+20.028}{13.043} & \mathrm{R}^{2}=0.94 \\
\text { for } \gamma^{\prime \prime}, & \log P=\frac{\log D^{\prime \prime}+26.238}{17.851} & \mathrm{R}^{2}=0.96
\end{array}
$$

where, in SI units, the temperature of exposure $\mathrm{T}$, is in ${ }^{\circ} \mathrm{K}$ and the time of exposure $t$, is in hours.

Equations 6 and 7, which gave the same relationship in British units, are correct as originally published.

1. S.T.Wlodek and R.D.Field, "The Effects of Long Time Exposure on Alloy 718", Superalloys 718, 625, and 706, Edited by E.A.Loria, TMS (1994), p.659-670. 